\title{
ANÁLISE DE VIABILIDADE DE MOTORES PNEUMÁTICOS EM VEÍCULOS
}

\author{
Johnny Martinez de Moraes ${ }^{1}$, Cristiane Aparecida Martins ${ }^{1}$, Susane Ribeiro Gomes ${ }^{1}$ \\ ${ }^{1}$ Instituto Tecnológico de Aeronáutica \\ E-mails: johnnymartinez9@gmail.com, cmartins@ita.br, susaneribeiro@gmail.com
}

\begin{abstract}
RESUMO
O uso de tecnologias de energias renováveis está se tornando competitivo economicamente em várias áreas da engenharia, entretanto há ainda um longo caminho pela frente em veículos automotivos. Sabe-se que a implantação de energia renovável e eficiência energética estão resultando em significante segurança energética, mitigação das mudanças climáticas e benefícios econômicos. Esta pesquisa foca no uso de motores pneumáticos para mover veículos automotivos. Primeiramente, são avaliadas as viabilidades ambiental, econômica e prática. Depois, autonomia, densidade energética e análise energética do ar comprimido são comparadas aos valores de fontes de energia usuais, como gasolina e etanol. Finalmente, os aspectos práticos da tecnologia são investigados, como os métodos de compressão do ar em altas e baixas taxas de compressão. Em resumo, o uso de ar comprimido é mais simples, barato e menos poluidor do que outros combustíveis. Esta pesquisa pretende ir além e mostrar os aspectos econômicos e práticos dessa tecnologia.
\end{abstract}

\begin{abstract}
A portfolio of renewable energy technologies is becoming cost-competitive in an increasingly broad range of circumstances, when it comes to vehicles there is a long road ahead. Rapid deployment of renewable energy and energy efficiency is resulting in significant energy security, climate change mitigation, and economic benefits. This research focuses on the use of pneumatic engines to move vehicles. Firstly, the environmental, economic and practical viabilities are assessed. Then, autonomy, energy density and energetic analysis of compressed air are compared to the values of usual energy sources, such as gas and ethanol. Finally, the practical aspects of the technology are investigated, such as methods of compressing the air in high and low compression rates. In summary, the use of compressed air is simpler, cheaper and less polluting than other fuels. This research intends to go beyond and show the economical and practical aspects of this technology.
\end{abstract}

\section{INTRODUÇÃO}

Cerca de $40 \%$ da poluição atmosférica nas grandes cidades é causada por veículos automotores, que emitem hidrocarbonetos; óxidos de nitrogênio; de carbono; e de enxofre, gases que poluem nossa atmosfera a cada dia. 
Soluções para o meio ambiente é o que muitos pesquisadores e empresas têm buscado. Uma das soluções pesquisadas é a utilização de motores pneumáticos em veículos automotores, movidos a partir de ar comprimido e emissão de ar atmosférico. Como consequência, os gases emitidos serão mais limpos que os de origem, devido ao filtro de ar do sistema de admissão do motor, contribuindo na diminuição da poluição atmosférica.

Além dos benefícios ambientais, esse tipo de motor tem grande vantagem econômica, comparado com o custo de combustíveis fósseis e biocombustíveis. O ar que abastece o veículo tem apenas o custo de energia do compressor e os custos do serviço. Os combustíveis fósseis e biocombustíveis têm oscilações de preço devido à oferta e demanda de cada produto, como historicamente podemos citar guerras, boicotes, crises, safras, pestes, estiagem, inundações e desfertilizações dos solos.

O ar que é utilizado nos motores, não necessita de nenhum processo de transformação, já que é o mesmo encontrado na atmosfera. Não havendo a necessidade de incremento de custos devido à usinas de álcool-açúcar; plantações de cana de açúcar ou milho; extratores de petróleo; refinarias de petróleo; transporte de combustíveis; oleodutos e gasodutos.

Com relação ao abastecimento dos veículos, como o ar está presente em todo o planeta, a rede de abastecimento pode ser muito bem distribuída em qualquer região, inclusive podendo ser móvel, para regiões onde a energia elétrica não está disponível.

Assim, do ponto de vista energético, o consumo total de energia para obter ar comprimido é muito menor do que o consumo total de energia para obter combustíveis usuais, como gasolina ou etanol.

\section{VEÍCULOS AUTOMOTIVOS}

Os veículos automotivos são os objetos de estudo para a aplicação do motor pneumático. É necessário conhecer as características do veículo para analisar a viabilidade da aplicação.

\subsection{Análise do espaço interno}

Motores a ar comprimido ocupam menor espaço que motores a combustão interna devido à sua simplicidade. Um veículo movido à combustão interna requer, no mínimo, os seguintes sistemas para seu funcionamento:

- Sistema de admissão de ar

- Sistema de injeção de combustível

- Sistema de ignição do motor

- Sistema de exaustão dos gases

- Sistema de arrefecimento do motor

- Sistema de controle do motor 


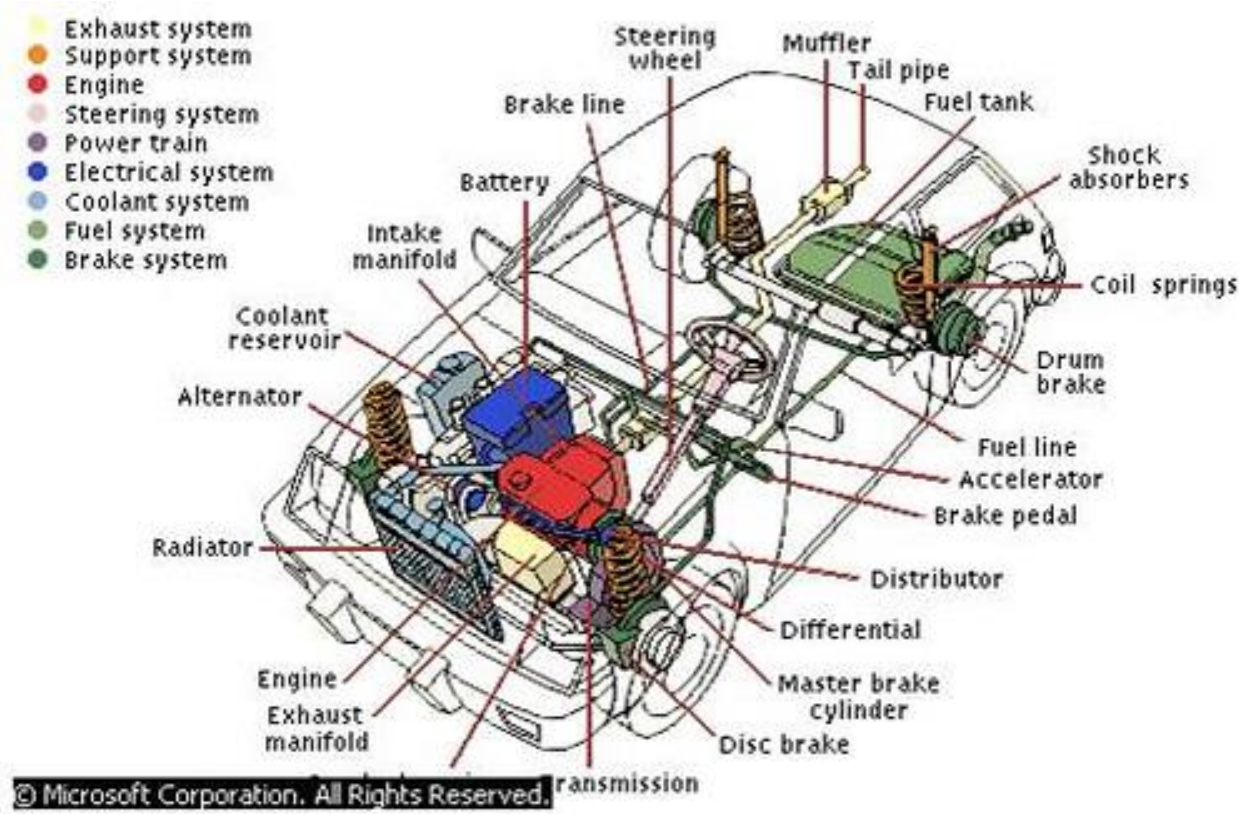

Figura 1 - Espaço interno ocupado por componentes do motor em veículo convencional

O motor a ar comprimido não necessita de sistema de ignição do motor e de sistema de arrefecimento do motor, ou seja, o motor a ar comprimido não necessita de velas, bobinas, radiador, bomba de água e ventoinha como o motor a combustão interna. Isso garante um maior espaço interno disponível na região do motor e menor massa do veículo, consumindo menos energia para se locomover.

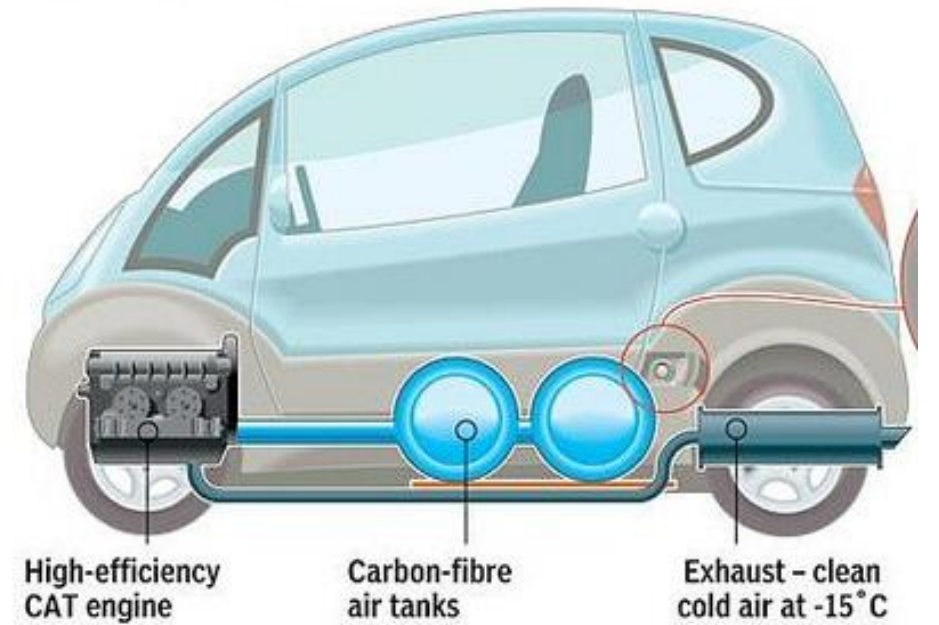

Figura 2 - Espaço interno ocupado por componentes do motor em veículo a ar comprimido

Por outro lado, o volume do cilindro de ar comprimido é maior do que um tanque de combustível, contrabalançando o espaço interno disponível. Enquanto um veículo a combustão interna tem um tanque a partir de 35 litros, um veículo a ar comprimido tem reservatório a partir de 200 litros. Porém, como a densidade do ar comprimido é menor, a massa nos dois casos pode ser considerada similar.

\subsection{Autonomia}

O método do ciclo urbano elementar (CUE), com duração de 195 segundos, é utilizado pela União Européia para avaliar a autonomia e eficiência de um veículo, onde são testadas as condições de acelerações, velocidades constantes e desacelerações. 


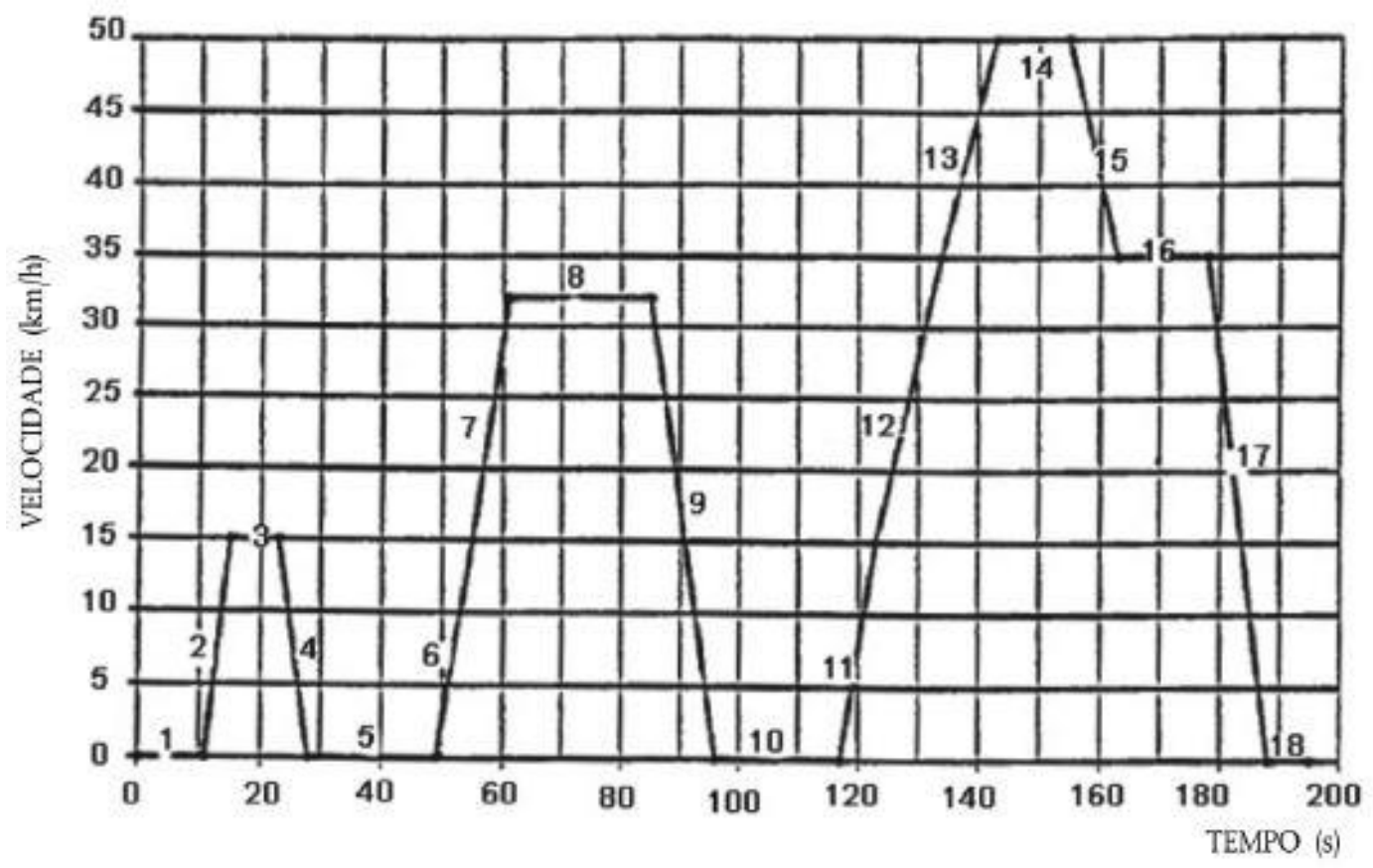

Gráfico 1 - Ciclo urbano elementar - 195 segundos

Tabela 1 - Ciclo urbano elementar

\begin{tabular}{|c|c|c|c|c|c|c|c|}
\hline \multirow{2}{*}{$\begin{array}{c}\text { Operação } \\
\text { no }\end{array}$} & \multirow[b]{2}{*}{ Tipo de operação } & \multicolumn{3}{|c|}{ CICLO URBANO ELEMENTAR } & \multirow{2}{*}{$\begin{array}{c}\text { Duração da } \\
\text { operação } \\
\text { [s] }\end{array}$} & \multirow{2}{*}{$\begin{array}{c}\text { Duração } \\
\text { do modo } \\
{[s]} \\
\end{array}$} & \multirow{2}{*}{$\begin{array}{c}\text { Tempo } \\
\text { total } \\
{[\mathrm{s}]}\end{array}$} \\
\hline & & Modo no & \begin{tabular}{|c|} 
Aceleração \\
{$\left[\mathrm{m} / \mathrm{s}^{2}\right]$}
\end{tabular} & $\begin{array}{c}\text { Velocidade } \\
{[\mathrm{km} / \mathrm{h}]}\end{array}$ & & & \\
\hline 1 & Parada & 1 & 0,00 & 0 & 11 & 11 & 11 \\
\hline 2 & Aceleração & 2 & 1,04 & $0-15$ & 4 & 4 & 15 \\
\hline 3 & Velocidade constante & 3 & 0,00 & 15 & 8 & 8 & 23 \\
\hline 4 & Desaceleração & 4 & $-0,83$ & $15-0$ & 5 & 5 & 28 \\
\hline 5 & Parada & 5 & 0,00 & 0 & 21 & 21 & 49 \\
\hline 6 & Aceleração & 6 & 0,69 & $0-15$ & 6 & 12 & 55 \\
\hline 7 & Aceleração & & 0,79 & $15-32$ & 6 & & 61 \\
\hline 8 & Velocidade constante & 7 & 0,00 & 32 & 24 & 24 & 85 \\
\hline 9 & Desaceleração & 8 & $-0,81$ & $32-0$ & 11 & 11 & 96 \\
\hline 10 & Parada & 9 & 0,00 & 0 & 21 & 21 & 117 \\
\hline 11 & Aceleração & 10 & 0,69 & $0-15$ & 6 & 26 & 123 \\
\hline 12 & Aceleração & & 0,51 & $15-35$ & 11 & & 134 \\
\hline 13 & Aceleração & & 0,46 & $35-50$ & 9 & & 143 \\
\hline 14 & Velocidade constante & 11 & 0,00 & 50 & 12 & 12 & 155 \\
\hline 15 & Desaceleração & 12 & $-0,52$ & $50-35$ & 8 & 8 & 163 \\
\hline 16 & Velocidade constante & 13 & 0,00 & 35 & 15 & 15 & 178 \\
\hline 17 & Desaceleração & 14 & $-0,97$ & $35-0$ & 10 & 10 & 188 \\
\hline 18 & Parada & 15 & 0,00 & 0 & 7 & 7 & 195 \\
\hline
\end{tabular}

De acordo com o ciclo urbano elementar, o torque e a potência necessários em cada veículo podem ser analisados. O consumo energético médio na cidade pode ser avaliado, pois o ciclo simula o percurso em trânsito urbano.

A potência de atrito (resistência ao rolamento), potência de arrasto do ar e a potência de aceleração devem ser calculadas com o objetivo de definir a potência necessária para o veículo executar o ciclo. 


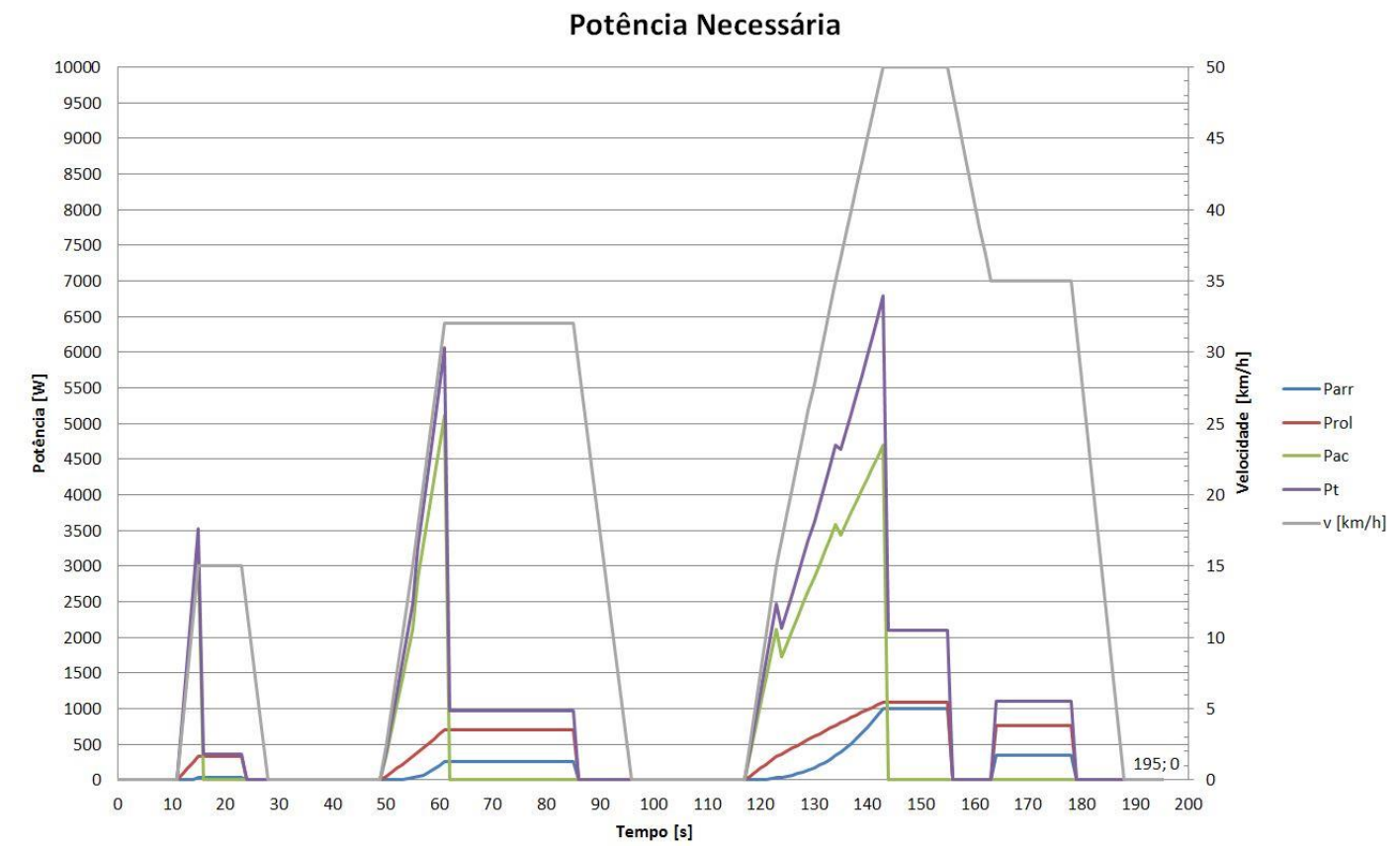

Gráfico 2 - Potência necessária no CUE 195s - MDI AirMini

O Gráfico 2 mostra as potências necessárias para o veículo MDI AirMini executar o CUE 195s. Devido às características próprias, cada veículo tem sua potência necessária para executar um ciclo. O Gráfico 3 mostra o comparativo entre os veículos MDI AirMini (ar comprimido) e o Fiat Palio 1.02016 (popular).

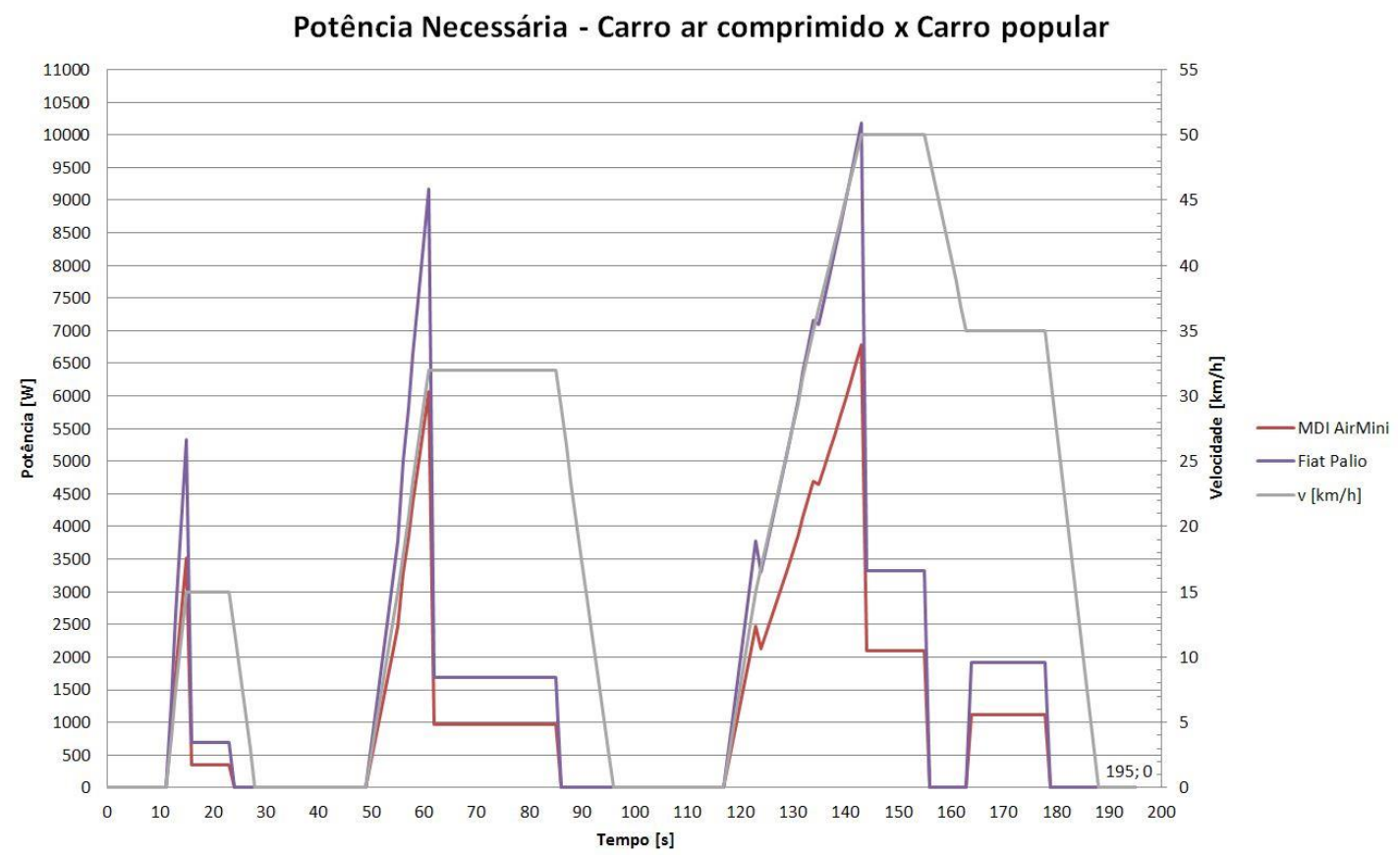

Gráfico 3 - Potência necessária no CUE 195s - MDI AirMini x Fiat Palio

O Gráfico 3 demostra que um veículo a ar comprimido necessita de menor potência do que um veículo popular, devido principalmente à simplicidade do motor, o que reduz o peso total do veículo.

Como desvantagem, se comparado com veículos atuais, veículos movidos a ar comprimido tem baixa autonomia. Isso também ocorre com veículos movidos a gás 
natural (GNV), pois o reservatório necessário para ambos os casos ocupa maior volume comparado com combustíveis líquidos, limitando suas autonomias.

\section{ENERGIA}

\subsection{Estudo energético global}

Para analisar a viabilidade de utilização de ar comprimido como fonte de energia para veículos, é necessário o estudo energético global comparando com outras fontes de energia com a mesma finalidade. Para isso, a Tabela 2 e a Tabela 3 mostram respectivamente a energia disponível pelos fluídos e o consumo de energia para tornalos disponíveis.

A Tabela 2 mostra a densidade energética das fontes de energia utilizadas para veículos, tanto em massa quanto em volume, pois o volume do reservatório também deve ser considerado para a análise de viabilidade do veículo.

Tabela 2 - Densidade energética dos recursos e comparativo com a gasolina

\begin{tabular}{|l|c|c|c|c|c|c|}
\hline Matriz & $\begin{array}{c}\text { Densidade } \\
{\left[\mathbf{k g} / \mathbf{m}^{3}\right]}\end{array}$ & $\begin{array}{c}\text { Dens. } \\
\text { Energ. } \\
{[\mathbf{k J} / \mathbf{k g}]}\end{array}$ & $\begin{array}{c}\text { Dens. } \\
\text { Energ. } \\
{[\mathbf{W h} / \mathbf{k g}]}\end{array}$ & $\begin{array}{c}\text { Dens. vol. } \\
\text { Energia } \\
{\left[\mathbf{k J} / \mathbf{m}^{3}\right]}\end{array}$ & $\begin{array}{c}\text { Razão DE } \\
\text { gasolina/ } \\
\text { fluídos }\end{array}$ & $\begin{array}{c}\text { Razão DVE } \\
\text { gasolina/ } \\
\text { fluídos }\end{array}$ \\
\hline Gasolina & 750 & 43540 & 12094,44 & 32655000 & 1 & 1 \\
\hline Diesel & 850 & 45600 & 12666,67 & 38760000 & 0,95 & 0,84 \\
\hline Etanol & 810 & 26400 & 7333,33 & 21384000 & 1,65 & 1,53 \\
\hline GNV (200 bar) & 130 & 53600 & 14888,89 & 6968000 & 0,81 & 4,69 \\
\hline $\operatorname{ar}$ (200 bar) & 238 & 445 & 123,61 & 105910 & 97,84 & 308,33 \\
\hline $\operatorname{ar}$ (300 bar) & 357 & 480 & 133,33 & 171360 & 90,71 & 190,56 \\
\hline ar (350 bar) & 416 & 492 & 136,67 & 204672 & 88,50 & 159,55 \\
\hline H2 (350 bar) & 22,9 & 142000 & 39444,44 & 3251800 & 0,31 & 10,04 \\
\hline Bateria Litio & 2000 & 558 & 155,00 & 1116000 & 78,03 & 29,26 \\
\hline
\end{tabular}

De acordo com a razão de densidade energética gasolina/fluidos descrita na Tabela 2, é possível afirmar que a gasolina tem mais energia disponível que o ar comprimido.

Considerando apenas a energia disponível, seria necessário um reservatório de cerca de 5584 litros de ar comprimido a 350 bar para ter a mesma autonomia que um veiculo à gasolina com tanque de 35 litros. Analisando apenas a frase anterior, pode dizer que o veículo a ar comprimido é inviável. Mas como explica a existência de veículos a ar comprimido com reservatório de 200 a 400 litros? A resposta é eficiência. Usando o Peugeot $1071.012 \mathrm{~V}$ (gasolina) como exemplo, o consumo é em torno de 9,4 kWh em um ciclo urbano [1], enquanto o MDI AirMini (ar comprimido) consome cerca de $0,9 \mathrm{kWh}$ para o mesmo ciclo [1], quase 11 vezes menos. Motores menores e menos potentes consomem menos energia que motores maiores e mais potentes no ciclo urbano. A autonomia do Peugeot 1071.012 V no ciclo urbano é de $636 \mathrm{~km}$ [1], cujo tanque é de 35 litros. A autonomia do MDI AirMini no ciclo urbano é de $127 \mathrm{~km} \mathrm{[1],}$ cerca de 5 vezes menor cujo reservatório é de 200 litros. Isso demostra que na prática, a razão de densidade energética entre gasolina e ar comprimido diminui consideravelmente no ciclo urbano, devido ao aproveitamento energético de cada veículo. 
Na região metropolitana de São Paulo, com exceção das estradas, a velocidade máxima permitida é de $70 \mathrm{~km} / \mathrm{h}$, podendo ser inferior. O enorme volume de carros contribui para essa região ser considerada de ciclo urbano. Veículos flex (que consomem gasolina e/ou etanol) tem consumo médio de $8 \mathrm{~km} / \mathrm{l}$ de etanol em ciclo urbano, obtendo autonomia de $400 \mathrm{~km}$ contando com um tanque de 50 litros ou 280 $\mathrm{km}$ com um tanque de 35 litros.

Além da densidade energética da fonte de energia para mover o veículo, é importante a densidade de consumo de energia requerida para gerar esse recurso. A Tabela 3 mostra a energia necessária para gerar a fonte de energia por unidade de massa e por unidade de volume.

Tabela 3 - Densidade de consumo de energia para geração dos recursos e comparação com a gasolina

\begin{tabular}{|l|c|c|c|c|c|c|}
\hline Matriz & $\begin{array}{c}\text { Densidade } \\
{\left[\mathbf{k g} / \mathbf{m}^{\mathbf{3}}\right]}\end{array}$ & $\begin{array}{c}\text { Dens. cons. } \\
\text { Energia } \\
{[\mathbf{k J} / \mathbf{k g}]}\end{array}$ & $\begin{array}{c}\text { Dens. cons. } \\
\text { Energia } \\
{[\mathbf{W h} / \mathbf{k g}]}\end{array}$ & $\begin{array}{c}\text { Dens. vol. } \\
\text { cons. En. } \\
{\left[\mathbf{k J} / \mathbf{m}^{\mathbf{3}}\right]}\end{array}$ & $\begin{array}{c}\text { Razão DCE } \\
\text { gasolina// } \\
\text { fluídos }\end{array}$ & $\begin{array}{c}\text { Razão DVCE } \\
\text { gasolina/ } \\
\text { fluídos }\end{array}$ \\
\hline Gasolina & 750 & 70565 & 19601,28 & 52923455 & 1 & 1 \\
\hline Diesel & 850 & 29331 & 8147,41 & 24931087 & 2,41 & 2,12 \\
\hline $\operatorname{ar}$ (200 bar) & 238 & 820 & 227,78 & 195160 & 86,05 & 271,18 \\
\hline $\operatorname{ar}$ (300 bar) & 357 & 906 & 251,67 & 323442 & 77,89 & 163,63 \\
\hline $\operatorname{ar}$ (350 bar) & 416 & 935 & 259,72 & 388960 & 75,47 & 136,06 \\
\hline H2 (350 bar) & 22,9 & 216000 & 60000,00 & 4946400 & 0,33 & 10,70 \\
\hline Bateria Litio & 2000 & 697,5 & 193,75 & 1395000 & 101,17 & 37,94 \\
\hline
\end{tabular}

De acordo com a razão de densidade de consumo de energia gasolina/fluidos descrita na Tabela 3, é possível afirmar que a gasolina tem maior consumo de energia para tornar-se disponível que o ar comprimido.

Analisando o estudo energético global das fontes de energia disponíveis utilizadas em veículos automotores foi possível concluir que o ar comprimido é viável como fonte de energia para essa aplicação.

\subsection{Consumo de energia do compressor}

O compressor de ar é o responsável pelo abastecimento dos reservatórios de ar dos veículos. A Figura 3 mostra o diagrama de abastecimento de ar comprimido, sistema semelhante ao utilizado para abastecimento de GNV.

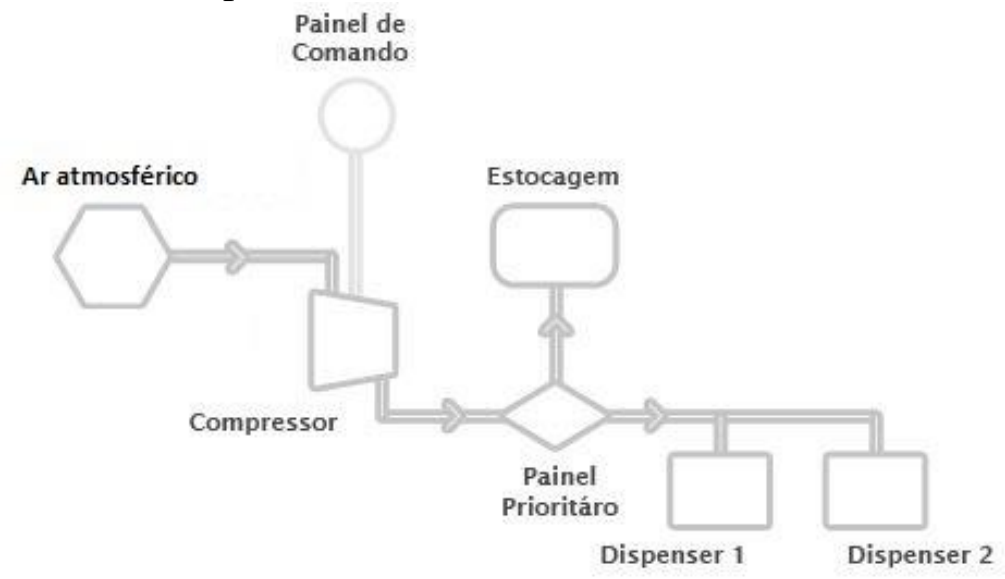

Figura 3 - Diagrama de abastecimento de ar comprimido 
Geralmente, o dispenser abastece o reservatório do veículo através do ar proveniente do reservatório de estocagem, sem consumo de energia, através de equilíbrio de pressões entre estocagem e veículo. Nos casos que o reservatório de estocagem estiver com pressão inferior a 350 bar, o abastecimento ocorrerá através de compressor, o qual possui consumo de energia. O cálculo de energia necessária para abastecer um veículo a ar comprimido é realizado considerando o abastecimento realizado por compressor, o qual é o caso mais crítico.

$\mathrm{O}$ processo de compressão é tratado como uma mudança de estado politrópica. A compressão do volume inicial de ar $V_{1}$ para o volume final do reservatório $V_{2}=V_{3}$ é seguida de remoção de calor no volume constante do reservatório $V_{3}$ de $\left(\mathrm{p}_{2}, \mathrm{~T}_{2}\right)$ para $\left(\mathrm{p}_{3}, \mathrm{~T}_{3}=\mathrm{T}_{1}\right)$, voltando à temperatura ambiente original $\mathrm{T}_{1}$. As condições finais $\left(\mathrm{p}_{3}, \mathrm{~T}_{3}=\right.$ $\left.\mathrm{T}_{1}\right)$ podem também serem alcançadas por uma compressão isotérmica ideal de $\left(\mathrm{p}_{1}, \mathrm{~V}_{1}\right)$. $\mathrm{O}$ trabalho consumido pela compressão isotérmica $\mathrm{W}_{\mathrm{t} 13}$ é igual à energia final disponível no reservatório independente do modo de compressão politrópica e arrefecimento isocórico. A energia de abastecimento é relacionada com a termodinâmica do processo de compressão. O limite menor é obtido pela isotérmica, o maior pela compressão isoentrópica (sem troca de calor) enquanto a politrópica está localizada entre as duas [2].

Os três processos de compressão são representados no diagrama pressão-volume (Gráfico 4) e no diagrama temperatura-entropia (Gráfico 5). Ambas as representações são comumente usadas por análises termodinâmicas [2].

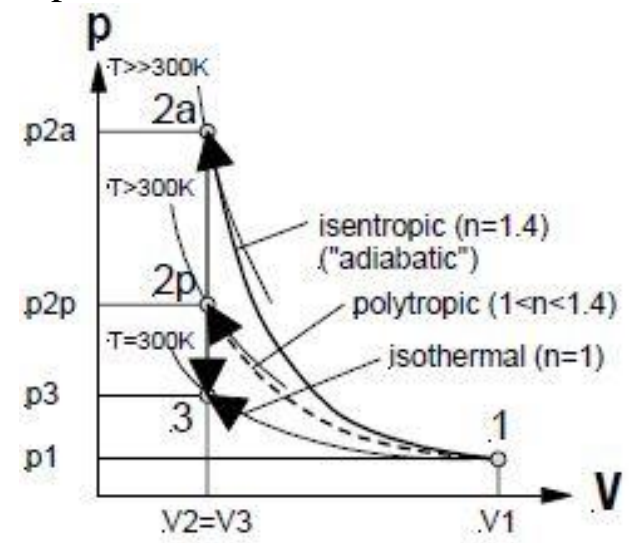

Gráfico 4 - Diagrama P-V da compressão do gás - 1 estágio

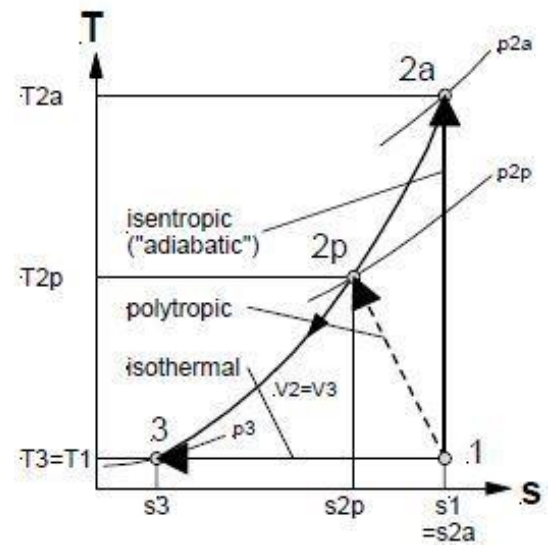

Gráfico 5 - Diagrama T-s da compressão do gás - 1 estágio 
Considerando a compressão isotérmica, o trabalho requerido para abastecer o reservatório pode ser calculado através da seguinte equação:

$$
W_{t 13}=W_{13}=p_{1} \cdot V_{1} \cdot \ln \left(\frac{p_{3}}{p_{1}}\right)=p_{1} \cdot V_{1} \cdot \ln \left(\frac{V_{1}}{V_{3}}\right)
$$

Onde:

$\mathrm{W}_{\mathrm{t} 13}$ Trabalho requerido para compressão isotérmica [J]

$\mathrm{p}_{1}$ Pressão inicial [Pa]

$\mathrm{p}_{3} \quad$ Pressão final $\quad[\mathrm{Pa}]$

$\mathrm{V}_{1} \quad$ Volume inicial do gás $\quad\left[\mathrm{m}^{3}\right]$

$\mathrm{V}_{3} \quad$ Volume final do gás $\left[\mathrm{m}^{3}\right]$

A mudança de estado politrópica segue as leis isoentrópicas. Todavia, o coeficiente isoentrópico ( $\gamma=1,4$ para ar) é substituído pelo coeficiente politrópico $\mathrm{n}$. $\mathrm{O}$ valor do coeficiente $n$ pode variar entre 1,4 para isoentrópico e 1,0 para isotérmico. $O$ ar é tratado como gás ideal [2].

Considerando a compressão politrópica, o trabalho requerido para abastecer o reservatório pode ser calculado através da seguinte equação:

$$
W_{t 12}=m \cdot c_{p} \cdot\left(T_{2}-T_{1}\right)=p_{1} \cdot V_{1} \cdot \frac{n}{n-1} \cdot\left[\left(\frac{V_{1}}{V_{3}}\right)^{(n-1)}-1\right]
$$

Onde:

$\mathrm{W}_{\mathrm{t} 12}$ Trabalho requerido para compressão politrópica $[\mathrm{J}]$

$\mathrm{m}$ Massa do gás [kg]

$\mathrm{c}_{\mathrm{p}}$ Calor específico do gás a pressão constante [J/kg.K]

$\mathrm{T}_{1}$ Temperatura inicial do gás [K]

$\mathrm{T}_{2}$ Temperatura do gás comprimido [K]

n Coeficiente politrópico do gás []

A pressão $\mathrm{p}_{2}$ e a temperatura $\mathrm{T}_{2}$ que são obtidos no momento final da compressão podem ser calculadas através das seguintes equações:

$$
\begin{aligned}
& p_{2}=p_{1} \cdot\left(\frac{V_{1}}{V_{3}}\right)^{n} \\
& T_{2}=T_{1} \cdot\left(\frac{V_{1}}{V_{3}}\right)^{\frac{n-1}{n}}
\end{aligned}
$$

Onde:

$\mathrm{p}_{2} \quad$ Pressão do gás comprimido [Pa]

Finalmente, a eficiência termodinâmica da compressão é definida pela razão entre a energia disponível no reservatório e o trabalho requerido para abastecimento do reservatório com ar comprimido [2]. 


$$
\eta_{t h}=\frac{W_{t 13}}{W_{t 12}}
$$

Onde:

$\eta_{\text {th }} \quad$ Eficiência termodinâmica [ ]

Definido o método de cálculo, podem-se definir as condições de referência, conforme Tabela 4:

Tabela 4 - Condições de referência

\begin{tabular}{|c|c|c|c|c|c|c|c|}
\hline \multirow{2}{*}{ Condição } & \multicolumn{2}{|c|}{ Temperatura } & \multicolumn{2}{|c|}{ Pressão } & Volume & Densidade \\
\cline { 2 - 5 } & {$\left[{ }^{\circ} \mathbf{C}\right]$} & {$[\mathbf{K}]$} & {$[$ bar $]$} & {$[\mathbf{P a}]$} & $\begin{array}{c}\text { Massa } \\
{\left[\mathbf{m}^{\mathbf{3}}\right]}\end{array}$ & {$\left[\mathbf{k g} / \mathbf{m}^{\mathbf{3}}\right]$} & {$[\mathbf{k g}]$} \\
\hline Inicial (1) & 20 & 293,15 & 1,01325 & 101325 & 69,085 & 1,2043 & 83,201 \\
\hline Final (3) & 20 & 293,15 & 350 & 35000000 & 0,2 & 416,003 & 83,201 \\
\hline
\end{tabular}

$\mathrm{O}$ trabalho requerido para abastecer o reservatório em compressão isotérmica ou a energia disponível no reservatório a 350 bar é de 40913 kJ.

Devido à taxa de compressão ser elevada (cerca de 350), o trabalho requerido por um compressor utilizando apenas um estágio é muito alto $(229.309 \mathrm{~kJ})$, tendo uma eficiência termodinâmica em torno de $18 \%$. Outro fator que inviabiliza esse tipo de compressor é a temperatura $\mathrm{T}_{2}$ atingida, cerca de $1284{ }^{\circ} \mathrm{C}$ (considerando o processo isoentrópico).

Em função dessa inviabilidade, podemos considerar um compressor de 4 estágios, que possui arrefecimento entre seus estágios, diminuindo o trabalho requerido e a temperatura máxima para a pressão desejada. Existem modelos comerciais que utilizam essa configuração.

O Gráfico 6 compara um compressor de 1 estágio e um compressor de 4 estágios em um diagrama T-s. Como a temperatura de compressão é muito menor no compressor de 4 estágios, o trabalho neste compressor é menor do que no compressor de 1 estágio.

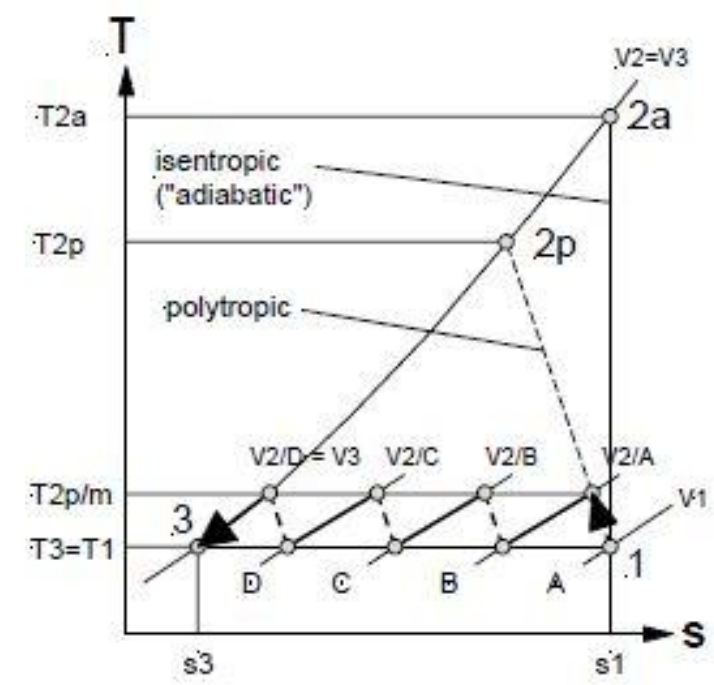

Gráfico 6 - Diagrama T-s da compressão do gás - comparativo entre 1 e 4 estágios

Considerando um compressor com coeficiente politrópico de 1,3 (valor aceito para compressores multi-estágios comerciais) e 4 estágios, o trabalho requerido para abastecer o reservatório é de $66753 \mathrm{~kJ}(18,5 \mathrm{kWh})$, temperatura máxima de $138^{\circ} \mathrm{C} \mathrm{e}$ 
eficiência termodinâmica de $61 \%$. Considerando que veículos elétricos têm maior trabalho requerido de recarga para autonomia similar, estes valores são favoráveis. E, com os avanços na tecnologia, essa eficiência tende a melhorar.

\section{CONCLUSÃO}

Essa análise se propôs à verificação da viabilidade de utilização de motores pneumáticos em veículos. Conforme parâmetros energéticos, ambientais e econômicos, foram constatados que esse tipo de veículo tem muitas vantagens, como baixo consumo de energia e custo para abastecimento, com menor tempo de abastecimento, menor custo de manutenção, e sem emissão de poluentes. Além disso, há grande abrangência de potenciais locais de abastecimento, permitindo até abastecimento residencial.

O motor pneumático tem muito a se desenvolver, podendo melhorar sua eficiência. Como exemplo de potencial melhoria, a expansão do ar comprimido em estágios, recuperando a temperatura da expansão de cada estágio para melhor aproveitamento da energia, principio inverso do processo de compressão em estágios, conforme Gráfico 6.

Sobretudo, esse tipo de propulsão vem simplificar o recurso para geração de energia e ajudar a minimizar os problemas ambientais do planeta, pois se continuarmos utilizando combustíveis fósseis, causaremos mais danos para nós e para as gerações futuras.

\section{REFERÊNCIAS}

[1] MDI. Comparative analysis. Disponível em:

http://www.mdi.lu/english/charge.php?nomfichier=Comparative-analysis.pdf. Acesso em: 21/02/2015.

[2] BOSSEL, Ulf. Thermodynamic analysis of compressed air vehicle propulsion. Journal of KONES Internal Combustion Engines 2005, Revised Version, Oberrohrdorf / Switzerland, vol. 12, pag. 51-62, 02/04/2009. 